\title{
COVID-19 and Soccer Teams on Instagram: The Case of Corporate Social Responsibility
}

\author{
Samuel Lopez-Carril \\ Universitat de València
}

\author{
Christos Anagnostopoulos
}

University Central Lancashire Cyprus

and Molde University College

\begin{abstract}
COVID-19 has given greater importance to the role of social media in sport, making it an essential way for fans to stay "in touch" with their teams. At the same time, the pandemic triggered additional actions from sport entities with the view to prove their commitment to society in an unprecedented moment of crisis. Professional team sport organizations have indeed initiated corporate social responsibility actions to collaborate in the fight against COVID-19. To explore these actions, the authors analyzed 3,906 posts on the official Instagram profiles of professional team sport organizations of La Liga (soccer, Spain), from March 11 to May 11, 2020, classifying them as philanthropic, sponsorship, or personnel engagement actions. The role of corporate social responsibility in a time of crisis and the potential of social media as a corporate social responsibility communication channel was also discussed.
\end{abstract}

Keywords: CSR, football, La Liga, social media

Sport's social and commercial values are indisputable, as is its communicative power. Common denominators and facilitators for these values within the organizational field of sport seem to be the ever-increasing practice of corporate social responsibility (CSR; Kolyperas, Anagnostopoulos, Chadwick, \& Sparks, 2016) and the utilization of social media (Schmidt, 2018). The former practice relates to a range of initiatives that seem to contribute to some social good, not required by law, which goes beyond the specific economic interests of the company (McWilliams \& Siegel, 2001). However, the COVID-19 outbreak has paralyzed the sports industry, not just in terms of the competition part of sport at the elite level, but also current sponsorship deals and broadcasting rights, employees'

\footnotetext{
López-Carril is with the Physical and Sports Education Dept., Universitat de València, Valencia, Spain. Anagnostopoulos is with the School of Business and Management, University of Central Lancashire Cyprus, Pyla, Cyprus, and the Faculty of Business Administration and Social Sciences, Molde University College, Molde, Norway. Anagnostopoulos (canagnostopoulos@uclan.ac.uk) is corresponding author.
} 
salaries (athletes and administrators alike), insurance companies, and a host of other stakeholders.

Every crisis offers opportunities to redefine (organizational) priorities, possibly by "seeking to investigate the positive processes, outcomes, and interpretations embedded in negative phenomena" (Cameron \& Spreitzer, 2013, p. 8). This is precisely what positive organizational scholarship puts forward by providing an organizing frame for research activity on positive states, outcomes, and generative mechanisms in individuals, dyads, groups, organizations, and societies (Anagnostopoulos \& Papadimitriou, 2017). So, when sports organizations-and, for that matter, professional team sports organizations (PTSOs) - are severely affected by a "disaster" like COVID-19, one may wonder what these PTSOs can do to turn such a disaster into something positive.

With this research-based scholarly commentary, the authors suggested that PTSOs can transform "bad" into "good" by using CSR's protective and deflective abilities, but also the abilities that collect, incorporate, and restore goodwill (Kolyperas et al., 2016). Moreover, Tilcsik and Marquis (2013) empirically demonstrated that disasters (natural ones, in their case) led to a punctuated increase of corporate philanthropy. At the same time, during the pandemic, social media have reinforced the spread presence they had in society. Social distancing has made people more (e-)connected. According to Statista (2020), time spent consuming social media outlets such as Facebook or WhatsApp increased by more than $40 \%$ worldwide during the COVID-19 outbreak. During this crisis, therefore, with hundreds of thousands of deaths, mental illnesses, job losses, and other negative issues associated with the pandemic, PTSOs can have an influential role in society, carrying out and communicating CSR actions toward the fight against COVID-19. As such, through social media, PTSOs' CSR becomes the mechanism by which public demands, expectations, and the confines of social acceptance and prestige can be detected, gathered, scanned, and fulfilled (Kolyperas et al., 2016).

\section{A Brief Background}

Society recognizes that sport, in many ways, has a powerful sense of social legitimacy (Bason \& Anagnostopoulos, 2015). The commercialization of sport has brought and pushed CSR to the soccer agenda as an instrumental medium, where social and environmental actions are performed as a means of reaching organizational goals (Schmidt, 2018). Several PTSOs have started taking social responsibility initiatives as a means of managing, organizing, and controlling the nonsporting dimensions of soccer (Pedersen \& Rosati, 2019). PTSOs do view such actions as an opportunity to strengthen their reputation and build trust among their community (Winand, Belot, Merten, \& Kolyperas, 2019). It is difficult to think of any other moment in the modern era of sport when PTSOs could do just that. The pandemic caused by COVID-19 constitutes one of those rare moments that the core product (i.e., playing and competing on the field) is being replenished almost exclusively by all other social, symbolic, and powerful abilities that PTSOs possess in the communities where they exist and operate.

The importance of disclosing these actions, however, should not be understated. In this regard, social media have emerged as a wide range of tools 
(YouTube, Facebook, Instagram, Twitter, etc.) that facilitate interactivity and cocreation, enabling the development and sharing of content among and between organizations and individuals (Filo, Lock, \& Karg, 2015). Organizations rely on social media to communicate their CSR initiatives (Dunn \& Harness, 2018).

The PTSOs have been early adopters of social media tools, aiming to enhance their awareness and build relationships with their fans (Parganas, Anagnostopoulos, \& Chadwick, 2017). In the context of CSR actions, this broad scope and the possibility of interaction reinforce the perception of organizational entities as transparent, open, and committed to their CSR initiatives (Dunn \& Harness, 2018). In addition, CSR messaging on social media can facilitate a halo effect that benefits sports entities in times of crisis (Kim, Ott, Hull, \& Choi, 2017). However, the extant literature has found that PTSOs' social media strategies have largely focused on product-related brand attributes (team success, players, coaches, etc.) rather than on nonproduct ones (values, image, sponsors, etc.; see Anagnostopoulos, Parganas, Chadwick, \& Fenton, 2018; Parganas et al., 2017). Indeed, as PTSOs' CSR activities are considered a non-product-related brand attribute, research has shown that only a small proportion of Instagram posts reflect community service activities such as promoting social initiatives (Anagnostopoulos et al., 2018). Thus, with the exception of the works of Hull and Kim (2016) and Kim et al. (2017), little is known about how PTSOs communicate their CSR actions through Instagram. Therefore, the authors asked the following question: How and to what extent do PTSOs use Instagram as a communication tool to disclose their CSR-COVID-19 actions?

In addressing the above-mentioned question, this commentary offers a twopronged set of insights. First, it explores, for the first time, the CSR-COVID-19 nexus in the context of PTSOs, thus shedding light on how sport contributes to society during an unprecedented time of crisis in the modern era of sport. Second, it shifts the focus of how PTSOs' social media can be used for non-product-related brand attributes that are concretely centered around philanthropic-based initiatives.

\section{Methods}

This exploratory study uses both quantitative and qualitative content analysis techniques to answer its research question. According to Riffe, Lacy, and Fico (2005), this type of analysis follows a systematic and reproducible method to analyze written and visual content. Content analysis has been widely employed in CSR research in sports settings (Bason \& Anagnostopoulos, 2015) and in studies focused on Instagram (e.g., Anagnostopoulos et al., 2018; Geurin-Eagleman \& Burch, 2016).

\section{Research Setting and Sample Selection}

The study draws on the PTSOs of La Liga (Spain), which is probably the most prominent soccer league in the world, along with the Premier League (England). Moreover, given the detrimental effects of COVID-19 in Spain, the authors assumed that the PTSOs would be likely to undertake and then communicate CSR actions linked to the COVID-19. 
The sample of this study is composed of the 3,906 posts collected from the official Instagram accounts of these PTSOs, published for a period of 2 months (March 11-May 11, 2020; see Table 1). Each of La Liga's PTSOs published an average of 195.5 posts, with an average of 390 comments and 65,437 likes per post.

\section{Data Collection and Coding Procedures}

The data were extracted using Phantombuster, a tool for obtaining data via application programming interfaces from social media and websites. All data were downloaded on May 13 through a CSV (comma separated values) file and then processed and refined manually to create an Excel database, which was used to calculate descriptive statistics. All photographs, videos, and text (but not Instagram's features, such as "stories" and "lives") of each post from the studied period were analyzed manually. This was done because, although Instagram is a platform where images and videos prevail, some posts did not clearly "picture" CSR actions. Therefore, the text of each post was an important complementary element to identify the CSR-COVID-19 actions.

The data analysis followed a deductive reasoning by using the predefined categories of the CSR-sport framework developed by Bason and Anagnostopoulos (2015) (see Figure 1). A random sample of 20 identified Instagram posts was analyzed by both authors. Given the language barrier of the second coder, and despite the use of a free translation website (deepl.com/translator), the intercoder reliability, assessed using Cohen's $\kappa$, was .577 , which can be assessed as a moderate level of agreement (Landis \& Koch, 1977). As this figure was below 0.7 , the coders discussed discrepancies to ensure consistency of understanding and interpretation. Another 10 randomly chosen posts were then coded again by both authors, leading to an acceptable intercoder reliability score of 0.878 . The rest of the coding was conducted by the first author. As mentioned, the categorization of the data was done based on the employed CSR-Sport conceptual framework, as CSR-COVID-19-oriented initiatives were assigned under first-order themes before proceeding to position them under second-order themes. Finally, the "beneficiaries" and "outcomes" were identified for each CSR-COVID-19 action identified.

During the sample coding process, three changes were made to the employed conceptual framework. The first one concerned changing the philanthropy subcategory "work with a sports charity" to "work with a charity," as the PTSOs collaborated with charity entities from outside the sporting context. The second change was to create the new personnel engagement subcategory "employees' inkind donations," as in many cases, the players themselves carried out these actions and not through the official channels of their PTSOs. Finally, a new "beneficiaries" subcategory named "COVID-19 fighters" was deemed necessary, as most CSRCOVID-19 actions were explicitly focused on public servants and volunteers (such as nurses, doctors, and police) who were "fighting" COVID-19 on the front lines. When CSR-COVID-19 actions fit into more than one theme, they were counted in each theme. For example, Real Betis Balompié produced medical equipment to help in the fight against COVID-19, thanks to the volunteer efforts from that PTSO. This action was categorized under "philanthropy" (within "in-kind donations"), as well as under "personnel engagement" (within "employees' volunteering"). 


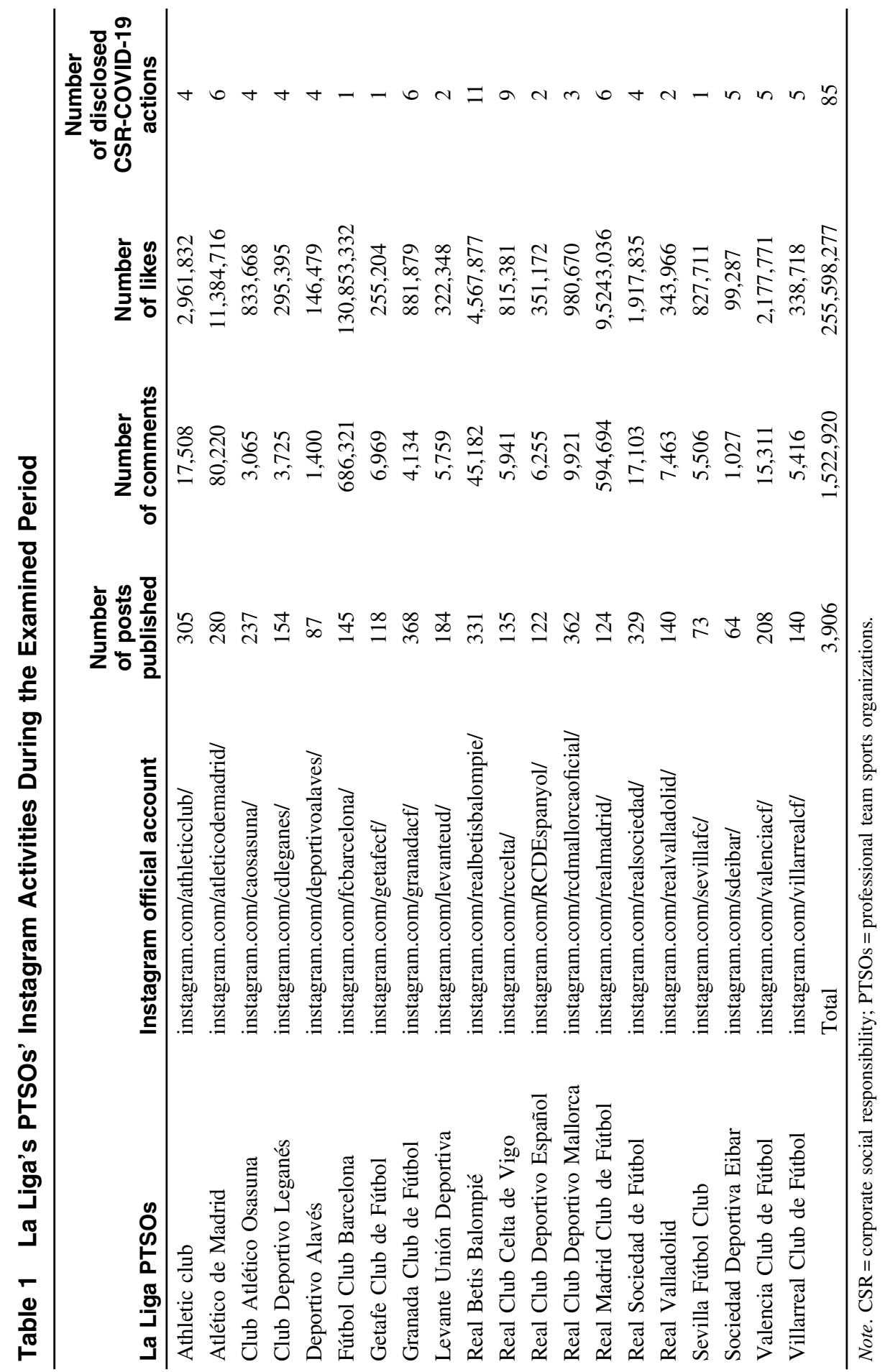




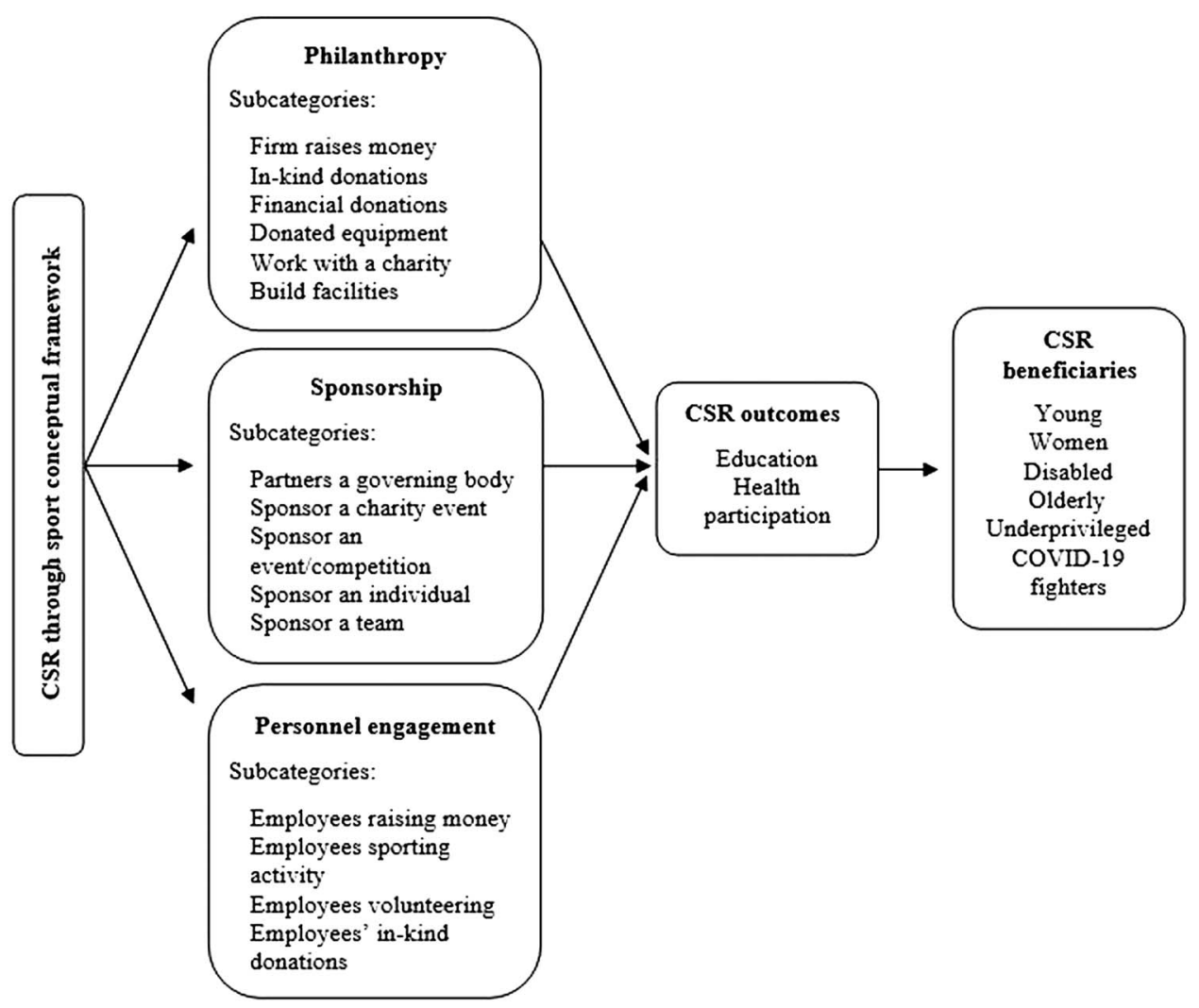

Figure 1 - Modified CSR through sport conceptual framework based on Bason and Anagnostopoulos (2015). CSR = corporate social responsibility.

\section{Results}

A total of 85 CSR-COVID-19 initiatives were disclosed through PTSOs' official Instagram accounts (see Table 1). All 20 PTSOs reported at least one CSRCOVID-19 action. Real Betis Balompié (11) and Real Club Celta de Vigo (nine) disclosed the most cases, whereas Sevilla Fútbol Club, Fútbol Club Barcelona, and Getafe Club de Fútbol disclosed just three in total. No posts fell into the "sponsorships" stream, probably because all PTSOs' competitions and associated activities (such as trainings) ceased during the studied period. Therefore, PTSOs and their sponsors have failed to orchestrate and then communicate sponsorship activations associated with COVID-19. One may expect these PTSOs' CSRCOVID-19 actions to appear in this stream once restrictions are removed.

By contrast, "philanthropic" CSR-COVID-19 actions stand out, with 71 cases, representing $84 \%$ of all identified cases. This finding seems to be in line with Tilcsik and Marquis's (2013) observation that, in times of disasters, a punctuated increase of corporate philanthropy occurs. Thus, in times of crisis, there is a need 
for a rapid philanthropic response, so financial or in-kind donations can be the most effective CSR initiatives in the short term. On the other hand, in the case of the "personnel engagement" stream, 14 cases were identified, representing $16 \%$ of all cases. Understandably, this number is not high, given the restrictive limitation on movement, as the majority of Spanish citizens were confined in their homes during the examined period.

\section{Philanthropy Stream}

Within the "philanthropic" stream specifically, the majority of CSR-COVID-19 actions (28, or 39\%) fell into the "raises money" category. For example, Atlético de Madrid, in collaboration with the Red Cross, launched the "\#LoDamosTodo" campaign that aimed to raise money with the purpose of purchasing medical equipment. In addition, most of the PTSOs participated in eSports FIFA20 competitions to raise funds. The most prominent was the "\#LaLigaSantanderChallenge" organized by La Liga in collaboration with (mainly) league sponsors. In this case, eSport, and for that matter, the FIFA20 soccer game, expectedly became one of the easiest means for PTSOs to interact with fans during the lockdown and get CSR-related messages across.

"Work with a charity" (19 cases, $27 \%$ of the total) and "in-kind donations" (16 cases, 22\%) were the second and third most representative substreams, respectively. For the former, the PTSOs collaborated with charitable organizations that were responsible for channeling all the support received. For example, Valencia Club de Fútbol and its players contributed financially to help the "Casa Caridad Valencia," a charity dedicated to housing and feeding people. Another example was Real Sociedad de Fútbol, which collaborated with the Hurkoa Foundation to help older people at home or persons with mental illnesses by providing them with various essential materials. As for the latter substream, Club Deportivo Leganés donated a new ambulance to the Spanish Civil Protection to help in the fight against COVID-19. Villarreal Club de Fútbol served more than 200 meals daily for hospital centers, to the military unit, and to religious organizations that support those in need. Finally, a total of four cases in "financial donations" ( $6 \%$ of the total), three cases of "built facilities" $(4 \%)$, and one case of "donated" equipment (1\%) were identified.

\section{Personnel Engagement Stream}

Regarding the "personnel engagement" stream, six cases of "employees' sporting activity" (43\% of the total) were identified. For instance, through its staff, Athletic Club conducted online exercise programs to motivate at-risk groups-the young and/or disabled - to undertake physical activity at home during the COVID-19 lockdown. The second most reported subtheme within this category was "employees volunteering," with four cases (29\%). For instance, Real Club Deportivo Español's employees created a phone service, calling all disabled people and over 75-year-old season-ticket holders to check that they were in good health and inquire about whether they needed any psychological or other support. This action also included having club employees voluntarily visit these people to provide food or medical supplies. 
The added substream "employees' in-kind donations" that was put forward during the sampled phase of the coding process reported three cases $(21 \%)$. These cases concern players who voluntarily made in-kind donations to a specific group of people or entity. For example, Emerson Aparecido, a Real Betis Balompié player, donated 150 food baskets to families in the favelas of Sao Paulo, where he had grown-up. Another example was Denis Suárez, a Real Club Celta de Vigo player, who supported the fight against COVID-19 with a donation of food and medical equipment to his hometown social services and to a hospital in Vigo. The last substream was "employees raising money," with the only one case (7\%) being Joel Robles of Real Betis Balompié, together with David Soria from Getafe Club de Fútbol. These players launched a crowdfunding campaign whose proceeds were used to support Getafe Hospital.

\section{Beneficiaries and Outcomes}

Naturally, the "beneficiaries" category was largely filled with the newly established substream of "COVID-19 fighters" (49 cases, 73\%). This substream included sanitary equipment, funding, food, and other resources that ensured that this group of people performs their difficult tasks with as much support as possible. Other beneficiary groups, albeit to a lesser extent, have been the focus of PTSO's CSRCOVID-19 initiatives communicated via their Instagram accounts. More specifically, the "under-privileged" and "elderly" substreams constitute two groups that are vulnerable to COVID-19, having both been the target of six related initiatives (9\% for each group). For example, Club Atlético Osasuna acquired 5,000 face masks that were later donated to club affiliates over the age of 65 years, as well as to residents of the senior centers El Solera Asistencia and the Residencia San Jerónimo de Estella. Athletic Club donated material and equipment for homeless people who have had to spend their quarantine period at several municipal sports halls.

Finally, regarding the "outcomes," the vast majority of actions (57 cases, 90\%) sought the improvement of "health" as their ultimate outcome. In just five cases $(8 \%)$ the specific aim was to encourage "participation" in sporting activities, through videos where the PTSOs' players and coaching staff performed and explained training. Although the initial purpose of these actions has been to encourage people to exercise at home during lockdown, it is clear that the physical and mental health of those beneficiaries/participants has been the ultimate goal. Only one CSR-COVID-19 case (2\%) had "education" as its outcome, but that has been a well-thought-through and powerful one (impact- and communication-wise alike). Sociedad Deportiva Eibar, in collaboration with the Red Cross, helped families in need by providing them with tablets and modems to enable children to attend online classes when all schools had to close down and school-based education was impossible.

\section{Concluding Comments and Take-Away Messages}

Undoubtedly, social media have transformed the ways in which PTSOs communicate, interact, and engage with a variety of stakeholders. The COVID-19 outbreak brought a crisis landscape in which the PTSOs have had the opportunity to strengthen their societal role and image and, thus, reinforce their legitimacy. 
Considering that only 85 out of 3,906 posts $(2 \%)$ have been devoted to CSRrelated initiatives by teams in one of the most popular soccer leagues in the world, one could argue that PTSOs have missed the opportunity to showcase (at the communication level) their societal role and have an impact on the most severe disruption the entire modern sport ecosystem has ever witnessed. Given the circumstances, any of these 85 mostly philanthropically based and health-oriented initiatives may have had a great impact on the targeted beneficiaries. However, it seems that the PTSOs' focus has been largely on their economic responsibilities (as per Carroll's [1979] CSR pyramid) — that is, finding ways to keep the organization viable-rather than exercising their ethical and discretionary responsibilities.

While this is understandable, some organizational slack during this "crisis" has been discerned. Interpreting the study's findings, some (albeit subjective) takeaway managerial messages for those administering PTSOs' CSR agendas and social media accounts are as follows:

a. In moments of severe disruptions and/or disasters, philanthropy is good. That is, altruistic behavior that is not necessarily aligned with PTSOs' core product(s). If anything (or if necessary at all), this altruistic behavior can be capitalized upon in the future through well-thought-out follow-up CSR initiatives.

b. If altruism is extremely difficult during such moments, creating a new generation of fans by steering all CSR initiatives toward them and generating social media content that mainly concerns PTSOs' product-related brand attributes may both be myopic. Carefully crafting CSR actions, as well as messages about non-product-related brand attributes that are centered around the elderly may be a smart move; these are often the ones that endorse youngsters' wishes (such as purchasing a new replica kit or a season ticket for the following year).

c. Integrate current sponsors (with one way or another and always with their consent) in all CSR actions and communications. In those moments, it is the PTSOs, not the sponsors, that have the communication power. Once things return to normal, "team-player" behavior is likely to be greatly appreciated.

d. Use the players/athletes as part of philanthropic campaigns, as PTSOs' communication power largely lies with them. Some players-often internationals, but not necessarily high-profile ones (as in the examples reported here)—wish to support certain causes and/or places. As long as their actions do not harm the PTSO's brand, do not stop them. Endorse and embrace their positive behavior; after all, this is additional content/story for a powerful post through the PTSO's official Instagram account.

e. During the complete lockdown, eSports have been considered a powerful mechanism to get positive messages across (such as fundraising), not least to reconnect family members by offering them a way of spending time together. A three-pronged approach through which CSR, social media, and eSports reach out to key stakeholder groups may be a smart way for PTSOs to be instrumental in their ethical and discretionary responsibilities.

To conclude, and despite its descriptive nature, the present research-based commentary has attempted to offer a positive dimension to this pandemic that has 
greatly affected the sport ecosystem. The study has certain limitations. The singlecase approach on all fronts (one sport, a specific league, one country, a single social media outlet) and the cross-sectional research design do not allow for generalizations. Finally, the emphasis was given to the communication of CSR-COVID19 cases, not to all CSR-COVID19 actions undertaken by PTSOs and which may not have been part of their Instagram posts. Nevertheless, the authors hope these empirical insights will keep the dialogue open regarding PTSOs' social responsibilities in moments of unprecedented crisis, what can be done in an impactful way, and what role social media outlets can play in scaling up such an impact.

\section{Acknowledgment}

S. López-Carril is grateful for the support received for a predoctoral study "FPU15/05670" granted by the Spanish Ministry of Science, Innovation and Universities.

\section{References}

Anagnostopoulos, C., \& Papadimitriou, D. (2017). Editorial: Positive organisational scholarship and behaviour in sport management. International Journal of Sport Management \& Marketing, 17(1/2), 1-6.

Anagnostopoulos, C., Parganas, P., Chadwick, S., \& Fenton, A. (2018). Branding in pictures: Using Instagram as a brand management tool in professional team sport organisations. European Sport Management Quarterly, 18(4), 413-438. doi:10.1080/ 16184742.2017.1410202

Bason, T., \& Anagnostopoulos, C. (2015). Corporate social responsibility through sport: A longitudinal study of the FTSE100 companies. Sport, Business and Management, 5(3), 218-241. doi:10.1108/SBM-10-2014-0044

Cameron, K.S., \& Spreitzer, G.M. (2013). Introduction. What is positive about positive organizational scholarship? In K.S. Cameron\& G.M. Spreitzer (Eds.), The Oxford handbook of positive organizational scholarship (pp. 1-14). New York, NY: Oxford University Press.

Carroll, A. (1979). A three-dimensional conceptual model of corporate performance. Academy of Management Review, 4(4), 497-505. doi:10.5465/amr.1979.4498296

Dunn, K., \& Harness, D. (2018). Communicating corporate social responsibility in a social world: The effects of company-generated and user-generated social media content on CSR attributions and skepticism. Journal of Marketing Management, 34(17-18), 1503-1529. doi:10.1080/0267257X.2018.1536675

Filo, K., Lock, D., \& Karg, A. (2015). Sport and social media research: A review. Sport Management Review, 18(2), 166-181. doi:10.1016/j.smr.2014.11.001

Geurin-Eagleman, A.N., \& Burch, L.M. (2016). Communicating via photographs: A gendered analysis of Olympic athletes' visual self-presentation on Instagram. Sport Management Review, 19(2), 133-145. doi:10.1016/j.smr.2015.03.002

Hull, K., \& Kim, J.K. (2016, September 22). How major league baseball teams are demonstrating corporate social responsibility on Instagram. The Sport Journal, 19, 1-8.

Kim, J.K., Ott, H.K., Hull, K., \& Choi, M. (2017). Double play! Examining the relationship between MLB's corporate social responsibility and sport spectators' behavioral intentions. International Journal of Sport Communication, 10(4), 508-530. doi:10. 1123/ijsc.2017-0081

Kolyperas, D., Anagnostopoulos, C., Chadwick, S., \& Sparks, L. (2016). Applying a communicating vessels framework to CSR value cocreation: Empirical evidence from 
professional team sport organizations. Journal of Sport Management, 30(6), 702-719. doi:10.1123/jsm.2016-0032

Landis, J.R., \& Koch, G.G. (1977). The measurement of observer agreement for categorical data, Biometrics, 33(1), 159-174. PubMed ID: 843571 doi:10.2307/2529310

McWilliams, A., \& Siegel, D. (2001). Corporate social responsibility: A theory of the firm perspective. Academy of Management Review, 26(1), 117-127. doi:10.5465/amr. 2001.4011987

Parganas, P., Anagnostopoulos, C., \& Chadwick, S. (2017). Effects of social media interactions on brand associations: A comparative study of soccer fan clubs. International Journal of Sports Marketing \& Sponsorship, 18(2), 149-165. doi:10.1108/ IJSMS-05-2017-087

Pedersen, E.R.G., \& Rosati, F. (2019). Organisational tensions and the relationship to CSR in the football sector. European Sport Management Quarterly, 19(1), 38-57. doi: $10.1080 / 16184742.2018 .1546754$

Riffe, D., Lacy, S., \& Fico, F.G. (2005). Analyzing media messages: Using quantitative content analysis in research (2nd ed.). Mahwah, NJ: Lawrence Erlbaum Associates, Inc.

Schmidt, H.C. (2018). Sport reporting in an era of activism: Examining the intersection of sport media and social activism. International Journal of Sport Communication, 11(1), 2-17. doi:10.1123/ijsc.2017-0121

Statista. (2020). In-home media consumption due to the coronavirus outbreak among internet users worldwide as of March 2020, by country. Retrieved from https:// www.statista.com/statistics/1106498/home-media-consumption-coronavirus-worldwideby-country/

Tilcsik, A., \& Marquis, C. (2013). Punctuated generosity: How mega-events and natural disasters affect corporate philanthropy in US communities. Administrative Science Quarterly, 58(1), 111-148. doi:10.1177/0001839213475800

Winand, M., Belot, M., Merten, S., \& Kolyperas, D. (2019). International sport federations' social media communication: A content analysis of FIFA's Twitter account. International Journal of Sport Communication, 12(2), 209-233. doi:10.1123/ijsc.2018-0173 